\title{
Sacrificial Protection for Architectural Heritage Conservation and Preliminary Approaches to Restore Historic Fair-Faced Brick Façades in China
}

\author{
Shibing Dai* and Yan Zhong \\ College of Architecture and Urban Planning, Tongji University, Shanghai, China \\ Cooresponding author: daishibing@tongji.edu.cn
}

\begin{abstract}
Sacrificial protection is a kind of active preventive intervention to conserve authentic fabric of architectural heritage, especially surfaces. This paper investigates the term of sacrificial protection and technical options, summarising that sacrificial plasters, shelter coating and plastic repair or re-pointing are three proven sacrificial protection measurements to conserve architectural surfaces. Two case studies show the preliminary approaches with help of sacrificial protection concept to restore historic fair-faced brick façades in China. Sacrificial protection concept did not originate from Chinese conservation practices, but it provides new prospects for sustainable conservation and revitalisation of architectural heritage. The implementation of sacrificial protection is still limited and more scientific studies are needed although most of approaches are traditional.
\end{abstract}

KEYWORDS sacrificial protection, preventive intervention, architectural heritage, fair-faced brick

Received December 5, 2018; accepted March 24, 2019.

Architectural heritage was built in the past and exposes to natural environment. The most authentic value of architectural heritage relies on their original fabric, which however deteriorates gradually due to physical, chemical, biological and even geological factors under natural climatic conditions or exposure to earthquakes. Those kind of environmental conditions usually do not allow to be changed or optimised. Or if the environmental conditions changed, uncontrolled damages will occur to the architectural heritage. A good example is the protection of architectural ruins.

From analysis of mistakes and successes done in the past, sacrificial protection technique has been implemented to use temporary measures or limited durable materials intentionally while treating or protecting valuable surfaces on monuments or precious buildings. It can be defined as active preventive intervention.

This paper tries to investigate the concept of sacrificial protection scattered in the international literature, guidelines or principles. Two case studies of practice in China are also analysed.

The concept of sacrificial protection should not be directly related to the material or the technique used.
Essentially and precisely, sacrificial protection should be a practical realistic solution strengthening that the target of restoration should be mainly focus on the protection of the authentic object.

\section{Learn from Mistakes: Sacrificial Protection}

Historical mistakes or successes from conservation practices show how using more durable repair materials can in some cases result in the accelerated deterioration of historic substances. It is also impossible to seal or chemically quarantine architectural heritage or even part of it from outside environment once for all and expect it to be immortal. In the past decades, some chemically sealed monuments have deteriorated heavily (Figure 1). In figure 1 , the deteriorated sandstone surface was consolidated and treated from hydrophic to hydrophobic 15 years ago. The initiate laboratory tests proved such treated sandstone was much more durable than untreated sandstone. However, the thermal and hygric delamination of sandstone which was built in the masonry has not improved, because the climatic conditions could not be optimised and 

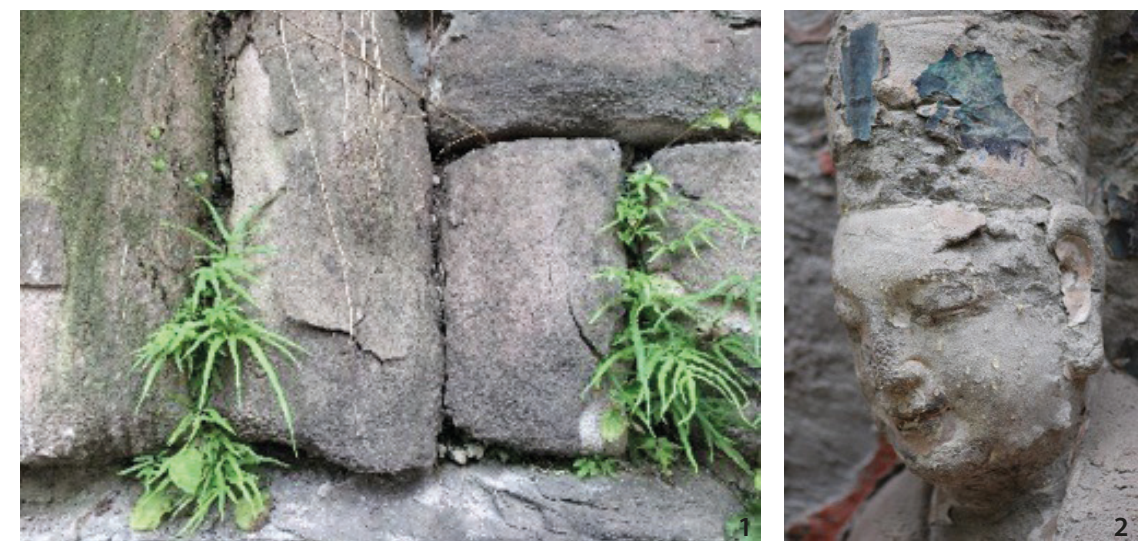

Figure 1 Sandstone of the former city wall in Chongqing built in Ming Dynasty, impregnated by methyl silicates and water repellents and peeled after 15 years later (Source: the author).

Figure 2 Condensation on the surface of a Buddha figure which is well sheltered against precipitation (Source: the author).

Figure 3 Fading of mural painting and accelerated stone deterioration of Buddha figure approximately 20 years after a so called 'environmental control measures', according to oral report of Fangying Li 2018 (Source: the author).

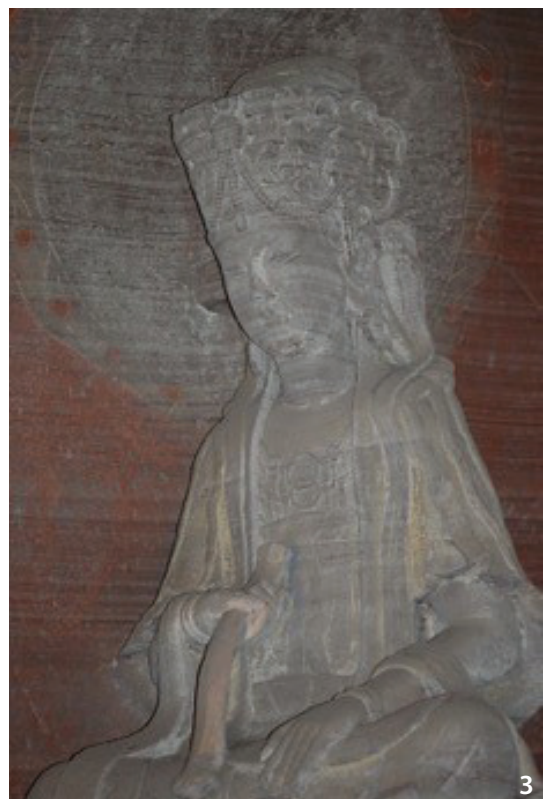

even became worse, for the chemical emission increased in the past two decades. The seepage water together with air-born pollution accumulates under the border between treated hydrophobic zone and hydrophic substrate, which causes disastrous material losses after one decade.

Another factor for the damages of monuments and buildings is condensation, which can hardly be eliminated and occurs often within or on the surface of monuments (Figure 2) and building envelops. Few researches indicate the impacts of highly $\mathrm{SO}_{2}, \mathrm{NO}_{\mathrm{x}}$ polluted air on condensation, but visual observation shows it can cause severe damage, and yellow drops of water are probably of good evidence.

In the past, some conservation practitioners tried to optimise the environmental conditions, for example, to lower the moisture level of grottoes of some cave temples, but these experiences ended up tragically in an unexpected manner. For example, existing mural paintings on the stone surface of cave temples faded much faster (Figure 3) after the ground water level had been dramatically lowered.

The concept of 'sacrificial protection' has been therefore implemented at the beginning of $21^{\text {st }}$ century in Europe, with the intention to advance in new perspectives of material conservation. However, the origins of the concept itself can be traced long ago to the approach of revarnishing painted surfaces cleaned, which is intentionally applied with a reversible protective coating and a buffer against weathering. In this sense, it is also important to acknowledge how historically architectural surfaces have been always periodically maintained for physical and aesthetic purposes. The resulting layers of plaster, renders, stain and washes related to this culture of maintenance constitute themselves a historic document and thus a key for the material authenticity of heritage assets, which has been put at risk since the introduction of modern techniques incorporating cement and plastic (Hammer 2006). One of the earliest documents that explicitly mentions the concept of sacrificial protection in architectural restoration is Heimann (1981) 'The treatment of salt-contaminated masonry with sacrificial render', where the render is used as compress to diminish the amount of soluble salts concentrated at the surface of the architectural surface. Eight years later, Koller (1989) published the article 'Denkmal-Pflege mit "Opferschichten", where he uses the term Opferschichten (sacrificial layer) with quotation marks referring generally to the Italian term strato di sacrificio. The term is originally deriving from a religious context, its literal translation of the Latin linguistic roots being to do a sacred thing, and which in the context means to designate the transfer of the impact of weathering from the original surface into a covering layer. The use of the term 'sacrificial' in this paper, therefore, does not aim to constitute a neologism for an old approach, but rather, to continue building upon Koller's understanding of the impact transfer ${ }^{1}$. Not only a covering layer can work as 'sacrificial' materials, but the surrounding counterparts or next to the historic substances like pointing.

One of the earliest technical guidelines that explicitly mentions the concept of sacrificial protection in architectural restoration is the Technical Note No. 37 Repointing Stone and Brick published by Environment \& Heritage Service in January 2006 (formerly named Repointing Stonework, April 1990), it states clearly that 'the strength 

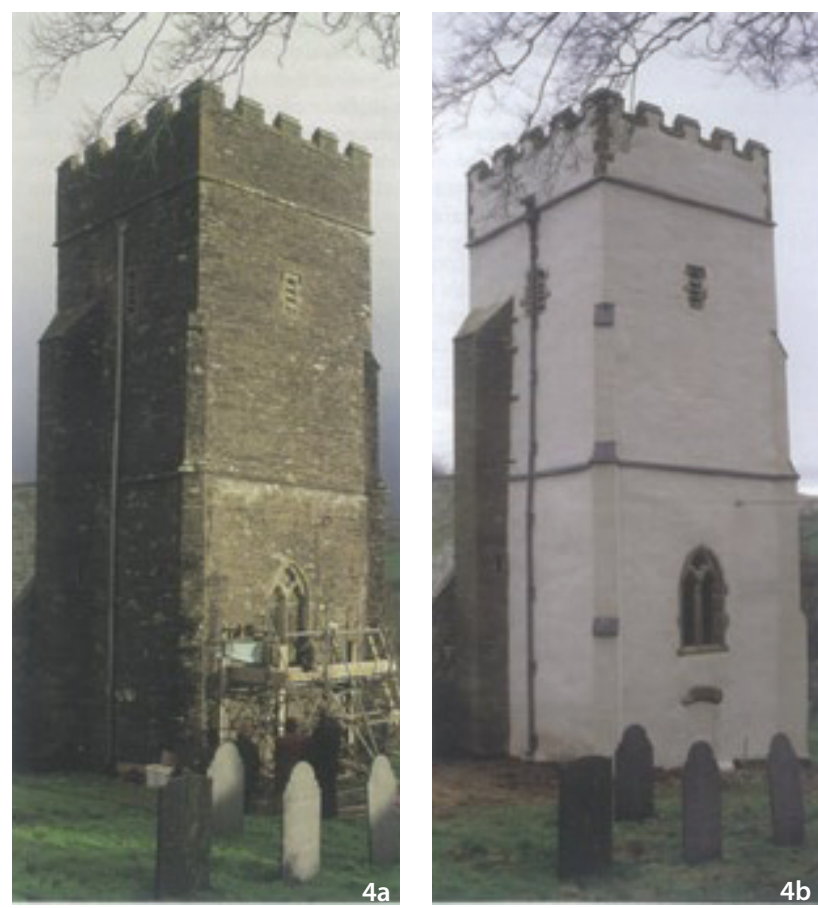

Figure 4 Holy Trinity Church, North Devon in 1994 (4a) and 1998 (4b) (Source: English Heritage: Mortars, Renders \& Plaster, 2011).

of the mortar should always be less than the surrounding stones and should be considered as a sacrificial element of the wall, and viewed as maintenance item in need of replacement possibly every century', though later researchers have proven that the time period of 5-10 years is more practical than 100-year periods (Environment \& Heritage Service 2006).

The same sacrificial protection guidelines can be found in the 2009 GHF Technical White Paper, which states that 'all materials, naturally occurring or man-made, will behave within different parameters depending on their qualities ... will sacrifice (itself) to other materials which may be described as harder, less porous or more tangible than the sacrificing material' (Global Heritage Fund 2009). Thus, the repair material should be softer, more porous and more hydrophilic than the historic elements to make sure these two combined materials will have a satisfactory behaviour which called compatibility, i.e., 'the inevitable onset of new deterioration process should be delayed as long as possible and that the restoration material should be the first to fail'. The GHF Technical White Paper also points out that former generations performed sacrificial restoration very well and probably intentionally, while we don't.

The concept of sacrificial protection highlights that proposed materials or new physical additions used for the conservation and restoration should be sacrificed to protect the original materials. With continuous monitoring and regular maintenance, the architectural heritage will be sustainably preserved and utilised. Sacrificial protection enables the ideal conservation principles like preventive conservation, minimum intervention or maintainability to be better realised in conservation practices.

Since 2010, it has almost become a standard recommendation to coat heavily salt-laden wall with sacrificial plasters in England (Figure 4). 'Such plasters should be designed to be weaker and more permeable than their substrate and fail sacrificially' (Henry and Stewart 2011, 211-212). In Germany, there are practices intentionally using sacrificial plaster from the 1990s (Auras, Meinhardt and Snethlage 2011; Dettmering and Kollman 2011). The physical performances can be optimised by using various binders (Hilbert 1995). In 2006 a guideline on sacrificial plaster (Merkblatt 2-10-06/ D, Opferputze) was published in Germany.

The concept of sacrificial protection is becoming more practically accepted in China. 'Mobihertage' (a Wechat official Account in China) reported to use sacrificial material based on natural hydraulic lime instead of cement for the Guyue Bridge restoration in Yiwu, Zhejiang Province, China. However, in China we are confronted with a problem that the original appearance of architectural heritage or monuments is not allowed to change, according the approved principles. Thus we are stuck in an awkward situation when answering a question like how to protect a historic masonry wall if it is exposed fully to a heavy traffic surrounding environment? (Figure 5)

\section{Options of Sacrificial Intervention to Conserve Architectural or Monument Surfaces}

The monitoring and evaluation of successful conservation reveals that to provide sacrificial materials over or next to historic substances is a very practical way. There are various options to implement sacrificial protection. Take the restoration of fair-faced brick as an example, at least three options can be considered. Option 1 is plastic repair and repointing with non-durable materials, for example lime mortars. Option 2 is staining or shelter coating. Option 3 is plastering, i.e. the authentic fabric is plastered by physically designed weak plaster.

\section{Option 1: Plastic Repair}

Plastic repair is to use soft porous repair mortars to reprofile damaged bricks instead of replacement. Mechanically the new mortars shall have higher water absorption, lower strength and less frost-thaw durability than original 

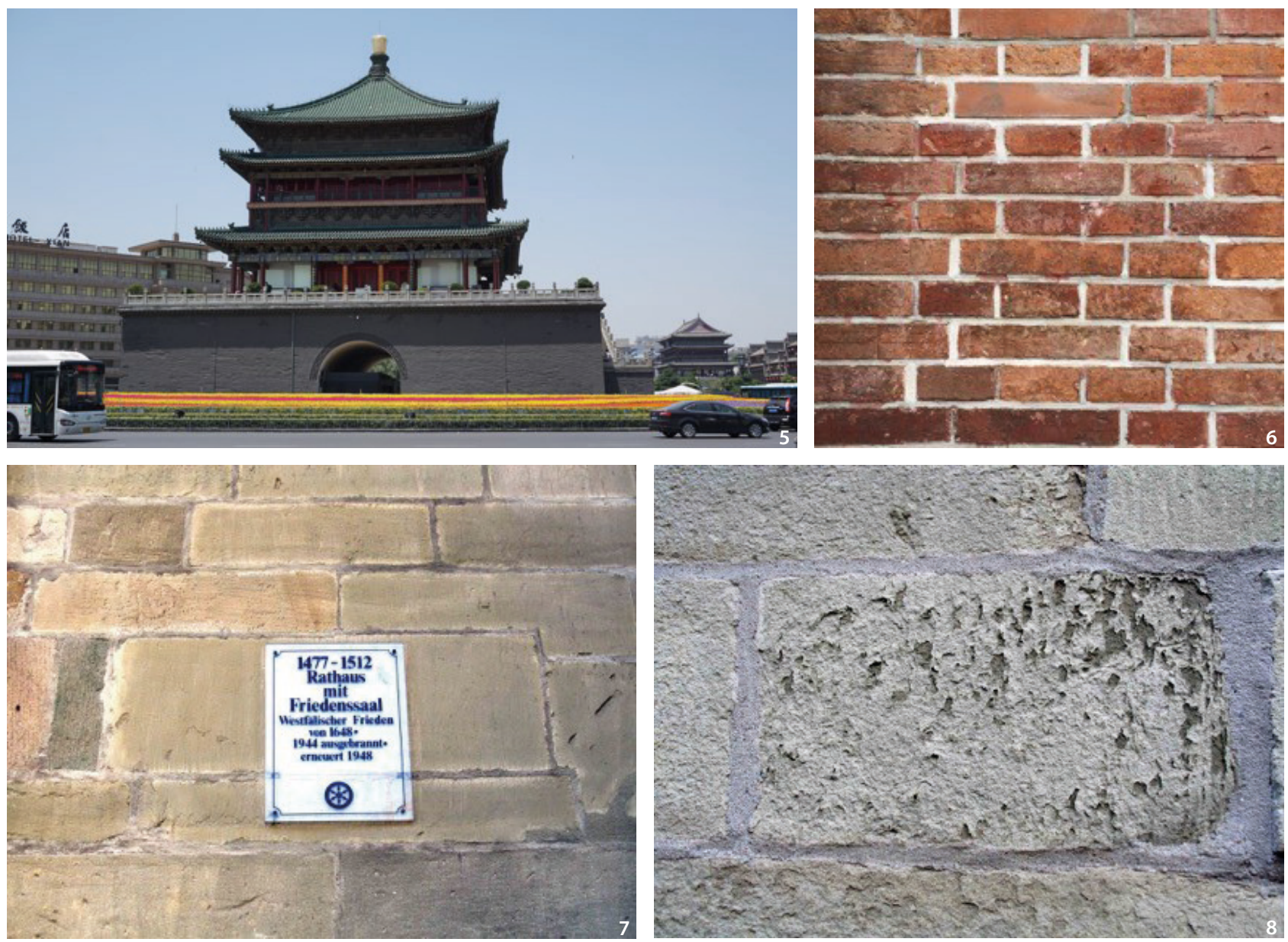

Figure 5 Xi'an Bell Tower, 2016. Actually, the masonry walls are covered with a very thin coat with thickness between plaster and coating and the original surface has been changed, however the thin coat has not been well designed as a protection layer and four walls have a very severe salt problem (Source: Yan Zhong).

Figure 6 Plastic repair and lime pointing as sacrificial measure (Source: the author).

Figure 7 Partial view of the eastern exterior wall about $1 \mathrm{~m}$ wide. After the latest restoration in 1983-1985, the façade stays in a satisfactory state of preservation during almost 25 years (Source: Auras, Meinhardt and Snethlage, 2011).

Figure 8 Partial view of the western exterior wall about 0.5 m shows the peeling of coating applied in 1985 (Source: Auras, Meinhardt and Snethlage, 2011).

bricks. The plastic repair mortar shall be free of harmful water soluble salts. The pointing mortars shall be even more less durable than repair mortars and shall be sacrificed first during the service lifespan of the restored architecture (Figure 6).

As binder, lime or natural hydraulic lime is preferred. The long time mechanical strength development of the repair mortars shall be considered.

\section{Option 2: Sacrificial Staining and Shelter Coats}

Sacrificial staining is application of a surface coating (from translucent to opaque) to architectural surface to reduce the water and air born pollutions (Auras, Meinhardt and Snethlage 2011). Such coatings can be lime-based like lime wash or modified organic resin, but all of them are not impregnate. The sacrificial staining has proven to be a very practical solution to protect very porous natural stone or brick.

A good case is the use of silicate and silicone emulsion coatings on the reed melle sandstone façade during 19831985, which stay on the stone surface instead of being absorbed into pore space like other coating materials. It has been proven that the coating protects well the original façade from weathering (Figure 7, Figure 8) (Auras, Meinhardt and Snethlage 2011).

It must be clearly emphasised that water repelling impregnation does not belong to sacrificial protection.

\section{Option 3: Sacrificial Plasters or Sacrificial Renders}

In most cases simple repointing is not enough to prevent rain water penetration or frost or salt damages from old fabrics successfully. Rendering may be the only option 
Table 1 The definition of sacrificial plaster in Merkblatt 2-10-06/D, Opferputze.

\begin{tabular}{|l|l|}
\hline Type & Characterisation after application \\
\hline OP-I & $\begin{array}{l}\text { The sacrificial plaster serves to prevent damage to surfaces from the effects of salts and moisture from inside the } \\
\text { masonry or component. Crystallisation/evaporation zones are displaced from the surface area of the substrate into } \\
\text { the sacrificial plaster or on its surface. }\end{array}$ \\
\hline OP-I-Salt compression & $\begin{array}{l}\text { The compress plaster is a special form of sacrificial plaster. It is designed for high salt deposition and can also be } \\
\text { used on heavily moistened substrates. }\end{array}$ \\
\hline OP-I-Moisture & $\begin{array}{l}\text { The sacrificial plaster serves for the temporary plastering of subsoils heavily exposed to moisture for a short time. } \\
\text { However, the plaster does not accelerate dehydration and must not be a 'barrier plaster' in its performance profile. }\end{array}$ \\
\hline OP-A & $\begin{array}{l}\text { The sacrificial plaster serves to protect previously damaged, sensitive and vulnerable surfaces against external } \\
\text { influences. With sufficient thickness, it can provide protection against weather (humidity, temperature), from } \\
\text { contamination (dusts, gases, splash water) and from mechanical or biological loads. }\end{array}$ \\
\hline
\end{tabular}

Table 2 Types of sacrificial plasters according to WTA-code of practice 2-10-06/D.

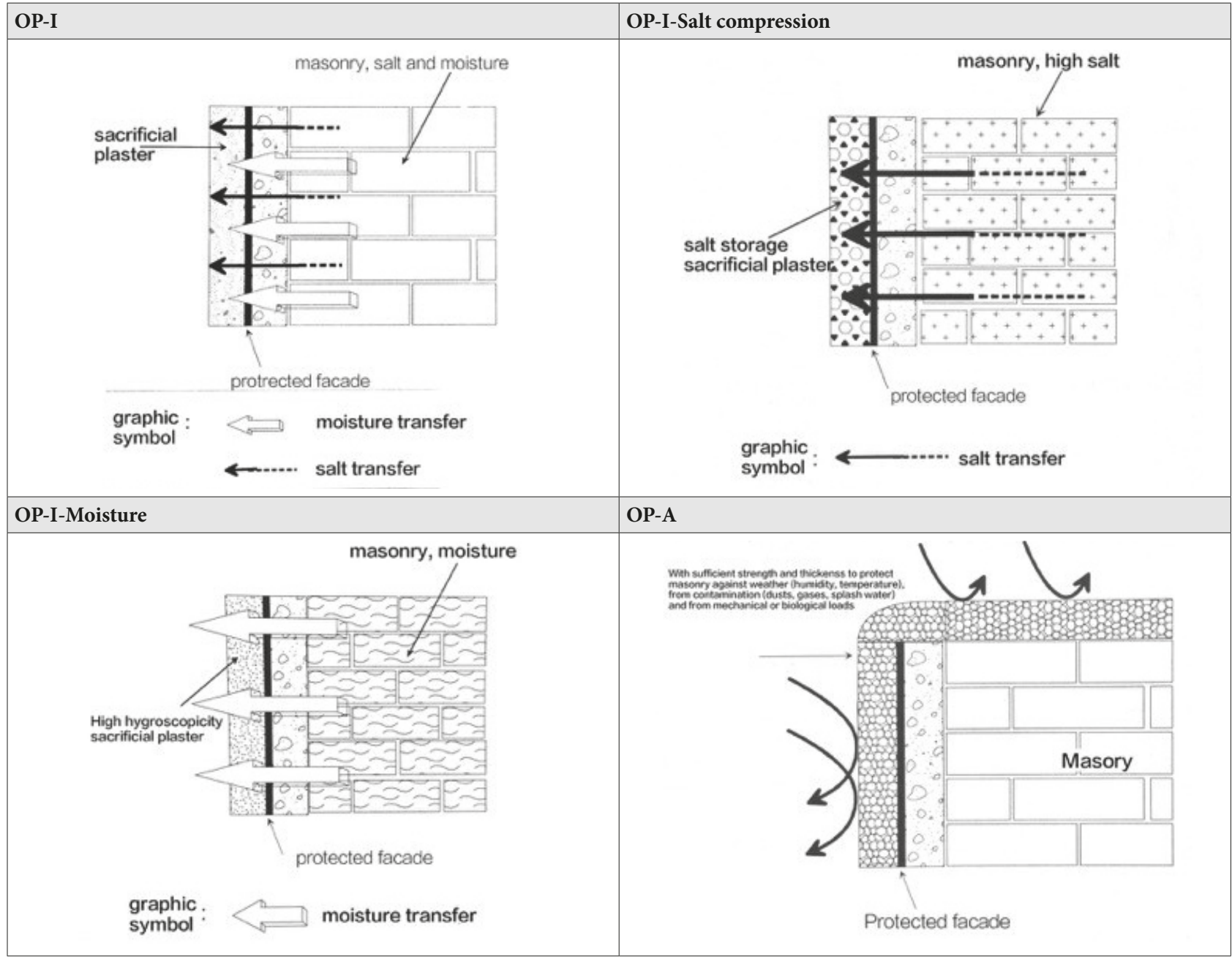

to protect surviving historic fabric or to make a building habitable again, even if it was not originally rendered. Sacrificial plasters have functioned well in the practices if they are physically designed and implemented.

In year 2006, WTA (Wissenschaftlich-Technische-Arbeitsgemeinschaft für Bauwerkserhaltung und Denkmalpflege) has set and published the technical guideline of sacrificial plaster (Merkblatt 2-10-06/D, Opferputze), which defines that 'sacrificial' plasters are plasters for temporary use to protect and treat the valuable surfaces on monuments or precious buildings (WTA 2006). Acknowledging the precision in claims from authors like Hammer (1985) and Ashurst (1990) to use the term 'compress plasters' for the temporary use of plasters to diminish salt concentration, we adhere to the WTA guideline, in which sacrificial plasters are divided into four main kinds according 

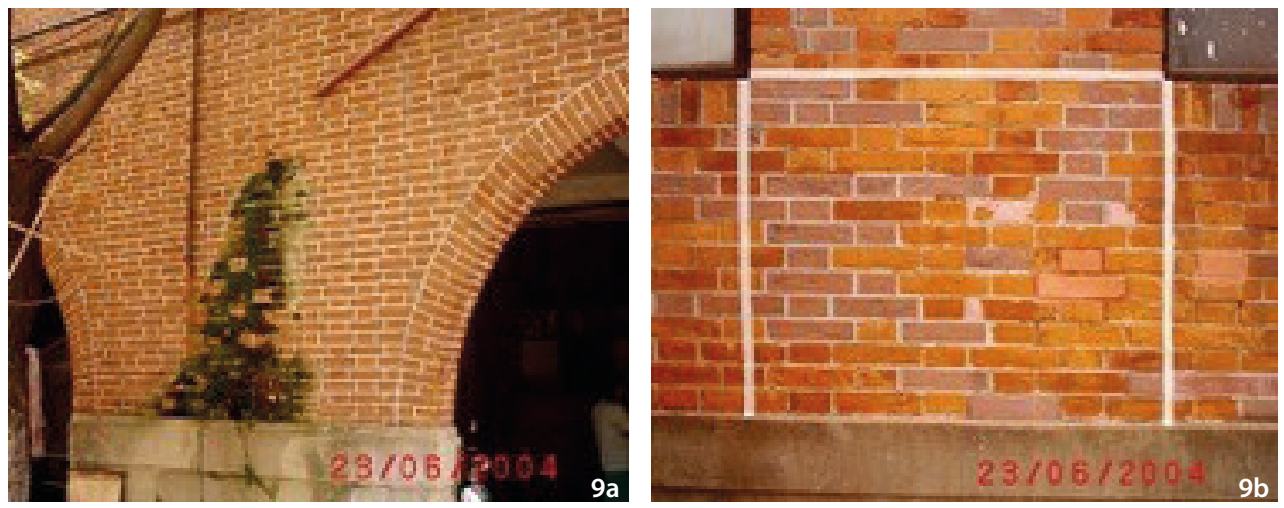

Figure 9 Fair faced brick façade of Jiangwan Stadium before restoration (Source: the author). Figure 10 Restoration measures of different bricks (Source: the author).

Figure 11 Bricks 12 years after restoration in Jiangwan Stadium, Octorber 2016 (Source: Liu
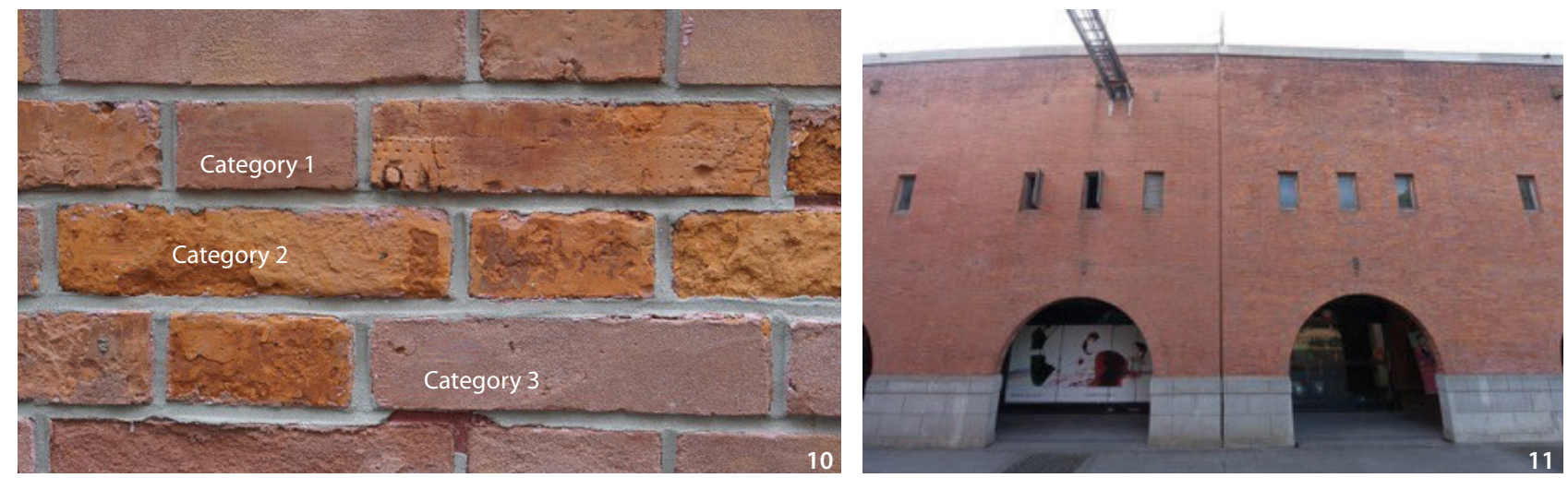

to their protection purposes including compress plasters themselves. For example, against attack from the environment as OP-A, from the outside or meant to be a treatment against internal material problems of the building component as OP-I. (Table 1, Table 2).

\section{Practice in China: Restoration of Fair- Faced Brick Façade}

\section{Jiangwan Stadium}

Jiangwan Stadium was built in 1934 as part of the Greater Shanghai Plan. It hosted the First National Games of China in 1935. During World War II the stadium was damaged by the Japanese during the Battle of Shanghai. The Kuomintang government repaired the stadium for the Seventh National Games in 1948.

As monument and remarkable heritage architecture, it was restored during 2004-2005. The fair-faced brick façade, totally over $20,000 \mathrm{~m}^{2}$, was one of the most important challenges for conservation works (Figure 9), because it was painted and suffered from heavy damages by rain water and improper usage.

After visual inspection of architectural materials and causes of defects, the restoration method statement had been specified. According to the specification, the brick façade was restored in 2005 as follows:
1. Removed paints using liquid solvent based paint remover together with high pressure water jet.

2. Removed all old repair mortars, cut and cleared all old joints.

3. Old bricks were classified into four categories according to their visual deterioration patterns (Figure 10).

Category 1: bricks without any visual deterioration: preservation without any intervention beside water repellent treatment.

Category 2: bricks with obvious deterioration, but the materials loss is less than $5 \mathrm{~mm}$ : preservation with treatment of ethyl silicate and solvent based water repellents.

Category 3: bricks with visual deterioration but the materials loss is less than $25 \mathrm{~mm}$, consolidation with ethyl silicate and repair with special consolidation mortars (plastic repair mortar, also called brick powder).

Category 4: bricks with visual deterioration, the materials loss more than $25 \mathrm{~mm}$ : replaced by old healthy brick.

The entire façade was impregnated with clear solventbased water repellents to reduce rain water penetration.

To match the colour between old and new plastic mortars, the applicators have mixed a brick-coloured stain on site and brushed onto the surface.

For the first time, it was specified that the compressive 

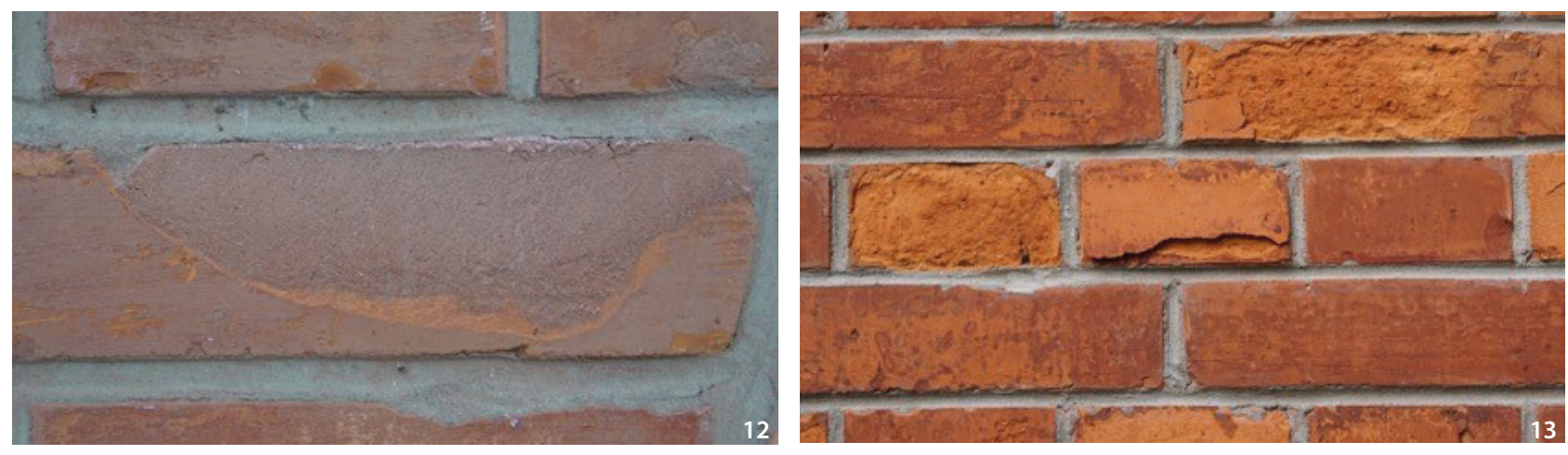

Figure 12 Attack by restoration plaster (Source: the author).

Figure 13 Delamination of old bricks after consolidation with ethyl silicate, the spalling may be related to frost (Source: the author).

strength of plastic repair mortars shall be lower than that of surrounding bricks. The repair mortars shall be more porous and deteriorate faster than brick, i.e., the new repair mortar should function as 'sacrificial' element to original brick. According to this requirement, a dry mix mortar based on Portland cement (approximately 10-15 $w t \%)$, red brick powder (10 wt\%), quartz sand and other additives, oxide pigments has been produced in four redyellowish tones.

The entire application work was scheduled for 8 months, but was shorted to 6 months shortly after the restoration work had started.

11 years after restoration, a visual inspection has been done by the author in October 2016. The façade of the Stadium itself was in good condition (Figure 11), but some bricks showed severe defects, which can be summarised as follows:

1. The strength of the new repair mortars seemed to be weaker than the old bricks, but there are some 'attacks' from repair mortars (Figure 12). This kind of 'attacks' may be caused by water soluble salts which existed in the cement-based repair mortar.

2. The pointing mortar seemed to be much stronger than repair mortar, although in most areas the joints were intact.

3. The consolidation with ethyl silicate may have contributed to the peeling or spalling of slightly deteriorated bricks (Figure 13). This could be caused by salts, high moisture content of the brick substrate or too low application rate. There were obvious efflorences, but desalination had not been considered within the specification.

4. Some spalling of original brick needs to be further studied.

It was first time in China in 2004, the conservation team from the Shanghai Administration of Cultural Heritage had proposed the technical parameters for brick façade restoration. The philosophy to use new weak material to restore historic substances can be defined as 'sacrificial protection' today. Although there was a lack of comprehensive researches before implementation neither after restoration, the mechanical strength of repair mortars was correctly formulated, cement is not the right binder.

The consolidation of with ethyl silicate might have reached less success due to substrate conditions are far more complicated than in the laboratory.

\section{Great Wild Goose Pagoda: Research Project during 2015-2016}

Because most of the brick façades in northern China had been deathly restored (Figure 14), i.e. the lively brick façade looks dead after restoration using replacement, a comprehensive research project, 'Conservation of Historic Brick Masonry in Arid Region', started in 2015 under the leadership of Shaanxi Provincial Institute of Cultural Heritage and Tongji University. This national research project was financially supported by the China National Cultural Bureau. Within the research framework, a 'sacrificial restoration' material system was developed to conserve historic masonry especially grey brick work in arid region. 'Sacrificial' has been officially used because it was deemed the most accurate way to explain the requirements to meet the principle 'repair rather than replacement'.

After comprehensive research works, a trial portion in the eastern elevation of Great Wild Goose Pagoda (Dayan Pagoda) in Xi'an was chosen as test area to observe the long-term effects.

The Great Wild Goose Pagoda, is one of two Tang Dynasty pagodas that still stand in Xi'an. It was built during the reign of Emperor Gaozong to store sutras and statues brought from India by Xuan Zang (604 AD-662 AD), Standing seven stories tall $(64 \mathrm{~m})$, the pagoda towers over the surrounding landscape and the Daci'en temple 

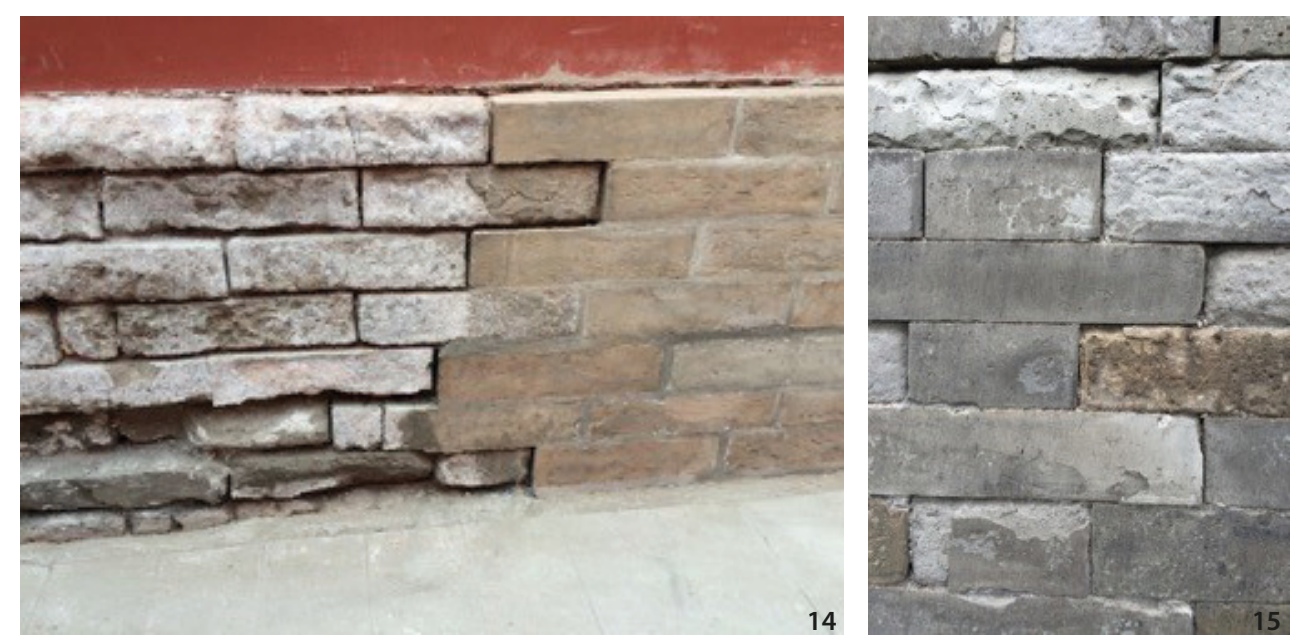

Figure 14 Ongoing restoration work in Beijing (2016), grey brick with high concentration of salts (most of them are gypsum and potassium nitrate) (Source: the author).

Figure 15 Typical deterioration of bricks of Dayan Pagoda (Source: the author).

Figure 16 Application of sacrificial materials on site (Source: the author).

Figure 17 One year after the restoration test of fair-faced brick wall of Dayan Pagoda in Xi'an under the research framework of the China National Cultural Bureau (Source: the author).
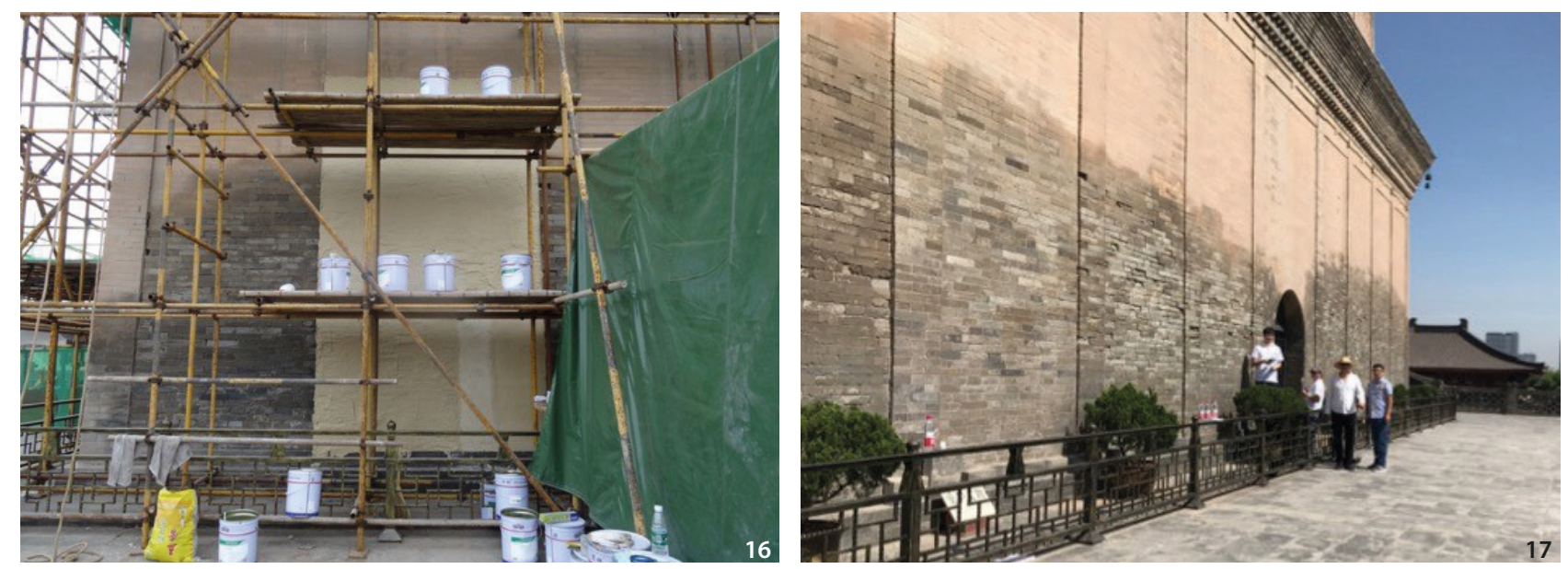

complex that has grown up around it. Originally it was a brick structure five stories tall, but in the year $704 \mathrm{AD}$ the two additional stories were added. The outer brick walls of the temple were added in the Ming Dynasty. Great Wild Goose Pagoda was listed as a World Heritage site in 2016 and is now a major tourist site in China.

The typical deterioration of the bricks in Great Wild Goose Pagoda is discoloration, powdering and peeling of bricks (Figure 15). The colour of grey bricks turns darker near the foundation or along eaves. The current maintenance method is to replace deteriorated bricks by new one.

After evaluation and laboratory testing, three types of sacrificial materials have been developed. The first one is desalination poultice based on clay minerals and paper fibres without any lime or organic binder. The second material is the repair mortar based on natural hydraulic lime (NHL) instead of cement. The third one is the pointing mortar based on a mixture binder of air lime (CL) and natural hydraulic lime.

A test area of approximately $4 \mathrm{~m}^{2}$ on the eastern façade has been restored as follows:

1. The entire surface was vacuumed, and especially all loose particles were removed by dry vacuum without any liquid water;

2. Apply desalination poultice by trowel on, leave for two weeks, remove it and repeat one time more. The salt content of brick surface has been tested before and after desalination.

3. Old bricks were classified into four categories according to their visual deterioration degrees and ultrasonic speed: Category 1: bricks without any visual deterioration, no intervention

Category 2: bricks with obvious deterioration, but the materials loss is less than $5 \mathrm{~mm}$, preservation as category 1 ;

Category 3: bricks with visual deterioration but the materials loss is less than $40 \mathrm{~mm}$, shall be reprofiled with developed mortars (plastic repair mortar based on NHL).

Category 4: bricks with visual deterioration but the materials loss is more than $40 \mathrm{~mm}$, shall be replaced by old healthy brick.

The entire façade was not consolidated either using ethyl silicate or other consolidates, neither impregnated with water repellents. 
To match the colour between old and new plastic mortars, soil water with few oxide pigments but without any binders was applied to new mortars.

The trial area has been completed in the summer of 2016 and will be monitored and evaluated before any further intervention or implementation to other areas.

\section{Discussion and Conclusions}

Sacrificial protection can be explained as an active preventive intervention to protect authentic fabric of architectural heritage or monuments which are expose to extreme climatic environment. Without any intervention, those monuments or architectural heritage may lose their values or disappear forever.

In terms of surface conservation of fair-faced brick façades there are at least three kinds of sacrificial protective measurements, i.e. sacrificial plastering, staining or coating and sacrificial mortar repair or repointing.

Sacrificial plaster are plasters for temporary use to protect and treat the valuable surfaces on monuments or precious buildings, which are divided into four main kinds according to the WTA-code of practice 2-10-06/D. Sacrificial plaster is very hard to be implemented as protective layer to brick façade even if those façades were once or for a long time plastered with lime. A few brick pagodas in China were restored with lime plaster coat but criticised because the lime plaster has 'changed' the appearance of the pagodas.

Sacrificial staining or shelter coats is the application of a surface coating (from translucent to opaque) to the architectural surface to reduce the water and air born pollutions. Such coatings can be lime-based like lime wash or modified organic resin, but all of them are not impregnation. To avoid the damages illustrated in the figure 3 , a sacrificial layer with a thickness between a plaster and shelter coats might be a practical solution.

Sacrificial protection is not a 'one for all' medicine, its application is also limited. Challenges of implementation of sacrificial protection are the approved national or international principles, exact technical or mechanical/chemical specification of all materials or measures and long term monitoring and evaluation.

As most architectural heritage still functions as a living building, it is not possible to limit restoration measures to those that '... do not interfere with the materials and structures of the items ... do not modify their appearance' (Van Balen 2016). According to the most relevant governmental principles and declarations about heritage conservation in China, the modification of appearance is forbidden. Those principles need to be updated especially under the consideration of the long term conservation and renewed life of the living architecture.

In the future more researches shall be done to explain the question how durable the sacrificial repair material should be, even though those kinds of approaches might be traditional materials or technique. More evaluation is also needed to differ good quality sacrificial protection from bad workmanship.

\section{Notes}

1. Thanks to the anonymous reviewers of this paper for the comments.

\section{References}

Auras, Michael, Jeannine Meinhardt, and Rolf Snethlage, eds. 2011. Leitfaden Naturstein-Monitoring: Nachkontrolle und Wartung als zukunftsweisende Erhaltungsstrategien [Guideline Natural Stone Monitoring: Follow-up and Maintenance as Forward-Looking Conservation Strategies]. Stuttgart: Fraunhofer IRB Verlag.

Dettmering, Tanja, and Kollmann Helmut. 2011. Putze in Bausanierung und Denkmalpflege [Plasters in Building Renovation and Historic Preservation]. Berlin: BeuthVerlag.

Environment \& Heritage Service. 2006. “Technical Note NO.37. Repointing Stone and Brick (formerly repointing stonework." Accessed 25 March 2019. https://www. communities-ni.gov.uk/sites/default/files/publications/doe/tn37-repointing-stone-and-brick.pdf

Global Heritage Fund. 2009. "Sustainable Preservation GHF's Model for Community Development-based Conservation." Accessed 25 March 2019. http://globalheritagefund.org/images/uploads/docs/GHFSustainablePreservationCommunityDevelopment.pdf

Hammer, Ivo. 1985. "Probleme der Erhaltung verputzter historischer Architektur." [Problems of Conservation of Plastered Historical Architecture.] In L'intonaco: storia, cultura e tecnologia [The Plaster: History, Culture and Technology], edited by Guido Biscontin, 339-352. Padova: Libreria Progetto Editore.

Heimann, J. L. 1981. The Treatment of Salt-Contaminated Masonry with a Sacrificial Render. Chatswood, N.S.W.: Experimental Building Station.

Henry, Alison, and John Stewart, eds. 2011. English Heritage Practical Building Conservation: Mortars, Plaster and Renders. Farnham: Ashgate Publishing. 
Hilbert, Georg. 1995. "Der Einfluss von Bindemitteln auf die Eingenschaften von Opferputzen." [The Influence of Binders on Sacrificial Plaster Properties.] Bautenschutz und Bausanierung 7: 71-75.

Koller, Manfred. 1989. "Denkmal-Pflege mit Opferschichten." [Monument Care with Sacrificial Layers.] In Österreichische Zeitschrift für Kunst und Denkmalpflege [Austrian Journal of Art and Historic Preservation], 43 (5): 48-52.

Van Balen, Koen. 2016. "Preventive Conservation of Historic Buildings. Restoration of Buildings and Monuments: Materials Science, Conservation of Architectural Heritage." Sustainable Construction 21 (3): 99-104.

WTA. 2006. Merkblatt 2-10-06/D, Opferputze [Sacrificial Plasters]. Fraunhofer: IRB Verlag. 